\title{
Butane Toxicity: The Curse of Volatile Solvent Abuse
}

\author{
Awais Tahir $^{\mathrm{a}}$ Petr Pokorny ${ }^{\mathrm{b}}$ Naveed Malek ${ }^{\mathrm{c}}$ \\ aDepartment of Acute Internal Medicine, Cambridge University Hospitals NHS Foundation Trust, Cambridge, UK; \\ ${ }^{b}$ Department of Neurology, Ipswich Hospital NHS Trust, Ipswich, UK; 'Department of Neurology, Queen's Hospital, \\ Romford, UK
}

\section{Keywords}

Butane toxicity Volatile substance misuse $\cdot$ Arrhythmias

\begin{abstract}
We discuss the presentation and management of a young person who presented to the emergency department with butane toxicity. A delay in recognition of butane toxicity can have fatal consequences. On the contrary, prompt recognition of the clinical scenario by physicians can lead to early commencement of appropriate treatment with a potential for full recovery.

(C) 2021 The Author(s)

Published by S. Karger AG, Basel
\end{abstract}

\section{Introduction}

Volatile solvent abuse, including that due to butane gas (contained in cigarette lighter fuel), is common among young people for achieving a quick "high" because of ease of availability of cigarette lighter fuel. Butane inhalation can cause brain permanent damage due to asphyxia. However, butane is also cardiotoxic and can cause both ventricular fibrillation as well as cardiac arrest.

karger@karger.com www.karger.com/dmj

Karger"
(C) 2021 The Author(s)

Published by S. Karger AG, Basel

This is an Open Access article licensed under the Creative Common Attribution-NonCommercial-4.0 International License (CC BY-NC) (http://www.karger.com/Services/OpenAccessLicense), applicable to the online version of the article only. Usage and distribution for commercial purposes requires written permission.

\section{Case Report}

A 25-year-old woman was brought in by ambulance to the accident and emergency (A\&E) department as a case of out-of-hospital cardiac arrest, but the exact time of onset was not known as the patient had been found unconscious in her bedroom. Taking a collateral history from the next of kin, there were no constitutional or systemic symptoms such as fever, night sweats, shortness of breath, or chest pain in the hours and days preceding her cardiac arrest. However, 2 empty canisters of butane gas (total $300 \mathrm{~mL}$ ) were found by her bed side.

On examination in the A\&E, her pupils were equal $(3 \mathrm{~mm})$ but sluggishly reactive to light. The Glasgow Coma Scale score was 5/15 (E1, V1, and M3). An electrocardiogram subsequently showed fine ventricular fibrillation which was terminated with direct electrical cardioversion, and she was given 2 ampoules of adrenaline intravenously. She was taken to the intensive care unit (ICU), intubated, and ventilated with $100 \%$ oxygen.

Laboratory tests on admission are shown in Table 1 . She had an electroencephalogram twice while off sedation, neither of which showed any evidence of seizure activity but did suggest she had a diffuse brain injury (Fig. 1). An MRI scan of the head after admission showed evidence of hypoxic-ischaemic brain injury (Fig. 2) and slightly high signal in basal ganglia (Table 2 for differential diagnoses [1]). A follow-up MRI scan after a month showed established bilateral occipital infarcts and brain atrophy (Fig. 3).

Once sedation was stopped after a couple of days in the ICU, she was left in an akinetic and mute state. The most distressing feature for the family was the florid post-hypoxic myoclonus. This took 
Table 1. Blood tests and other laboratory tests on admission and in ICU

1. Full blood count: $\mathrm{Hb} 125 \mathrm{~g} / \mathrm{L}$ (normal 115-160), WBC $9.7 \times 10^{9} / \mathrm{L}$ (normal 4.0-11.0), and platelets $236 \times 10^{9} / \mathrm{L}$ (normal 135-450)

2. Serum electrolytes: sodium $137 \mathrm{mmol} / \mathrm{L}$ (normal 135-145), potassium $3.8 \mathrm{mmol} / \mathrm{L}$ (normal 3.5-5), chloride $107 \mathrm{mmol} / \mathrm{L}$ (normal 95-105), calcium $2.34 \mathrm{mmol} / \mathrm{L}$ (normal 2.20-2.60), phosphate $0.92 \mathrm{mmol} / \mathrm{L}$ (normal 0.8-1.5), and magnesium $0.96 \mathrm{mmol} / \mathrm{L}$ (normal 0.7-1.0)

3. Coagulation profile: prothrombin time $11.1 \mathrm{~s}$ (normal 10-15) and activated partial thromboplastin time $22 \mathrm{~s}$ (normal 26-37)

4. Urea and creatinine: $3.8 \mathrm{mmol}$ (normal 2.5-7.8) and $67 \mu \mathrm{mol} / \mathrm{L}$ (normal $45-84$ )

5. Liver function tests: total bilirubin $7 \mu \mathrm{mol} / \mathrm{L}$ (normal 0-20), albumin $47 \mathrm{~g} / \mathrm{L}$ (normal 35-50), and ALT 101 units/L (normal 0-33)

6. C-reactive protein: $12 \mathrm{mg} / \mathrm{L}$ (normal $0-5)$

7. Blood glucose: $4.8 \mathrm{mmol} / \mathrm{L}$ (normal 3.0-6.0)

8. Blood culture: no growth

9. Creatinine kinase $570 \mathrm{U} / \mathrm{L}$ (normal 0-180)

10. Plasma paracetamol $<10 \mathrm{mg} / \mathrm{L}$ and salicylate $<10 \mathrm{mg} / \mathrm{L}$

11. Venous blood gases: pH 7.39, PCO2 $5.95 \mathrm{kPa}, \mathrm{pO} 23.9 \mathrm{kPa}, \mathrm{HCO} 326 \mathrm{mmol} / \mathrm{L}$ (showed no evidence of acidosis or alkalosis)

12. CSF examination: 2 lymphocytes, 1 red blood cell, 1 polymorphonuclear white blood cell, and no organism seen

13. Blood culture: no growth

14. ECG (12-lead ECG): prominent R waves V1-3 and ST depression V2 V3

CSF, cerebrospinal fluid; ECG, electrocardiogram.

several days to control with escalating dose of several anti-epileptic drugs (levetiracetam, sodium valproate, and clonazepam). She spent a nearly month on the ICU and required a tracheostomy but was able to breathe spontaneously. She had nasogastric tube feeding and regular physiotherapy but remained cognitively impaired with a Glasgow Coma Scale score of 6/15 (E4, V1, and M1) and tetraplegic. She spent a further 3 weeks on the neurology ward for neurorehabilitation where she had a percutaneous endoscopic gastrostomy and was later transferred to a long-term rehabilitation facility as there was no further improvement in her clinical state.

\section{Discussion/Conclusion}

Volatile solvent abuse is one of the most common forms of drug abuse in the 11-15 year age group in England and Wales. It is estimated that in the UK, 3.5-10\% of young people have at least experimented with volatile solvents and that $0.5-1 \%$ are current users of volatile solvents [2]. Butane (and isobutane), which is a component of cigarette lighter fuel, can be easily abused because cigarette lighters and lighter fuel are not contraband. One of the major pathophysiological mechanisms of butane toxicity to the brain is related to asphyxia, which is due to the displacement of oxygen by butane in the lungs [3]. This can result in permanent and severe brain damage due to hypoxia. Butane also seems to have a cardiotoxic effect and can induce ventricular fibrillation and subsequent cardiac arrest [4] as we report in our case.

Toxicological examination, where no clear history is available, can be used to confirm butane gas in blood and urine samples by means of gas chromatography [5]. How-

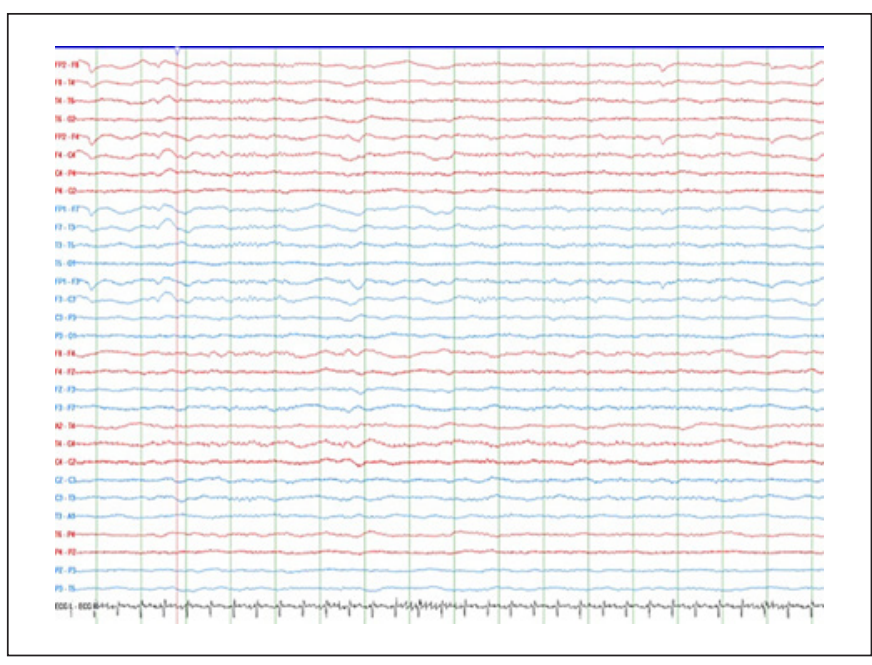

Fig. 1. Patient's EEG while off sedation; there is generalized slowing, and the wave morphology is of low amplitude, but no epileptiform activity or electrographic seizures are seen (even numbers represent right sided leads while odd numbers represent left side leads). EEG, electroencephalogram.

ever, if there is a long delay in sending blood samples to the appropriate laboratory, butane can still be detected in adipose tissue at autopsy up to 2 weeks after death from suspected butane inhalation [6]. Since we had a clear history of butane abuse and no exposure to any other toxins or burning stoves or gas heaters, we did not request chromatographic analysis of blood samples for butane or request carboxyhaemoglobin levels in blood. Unfortunately, there are no specific antidotes for inhalant intoxication [7]. 
Fig. 2. Patient's MRI head scan (T2WI on the left and DWI on the right) 4 days after hospital admission with restricted diffusion of the occipital lobes (circled). T2WI, T2-weighted image; DWI, diffusionweighted image.
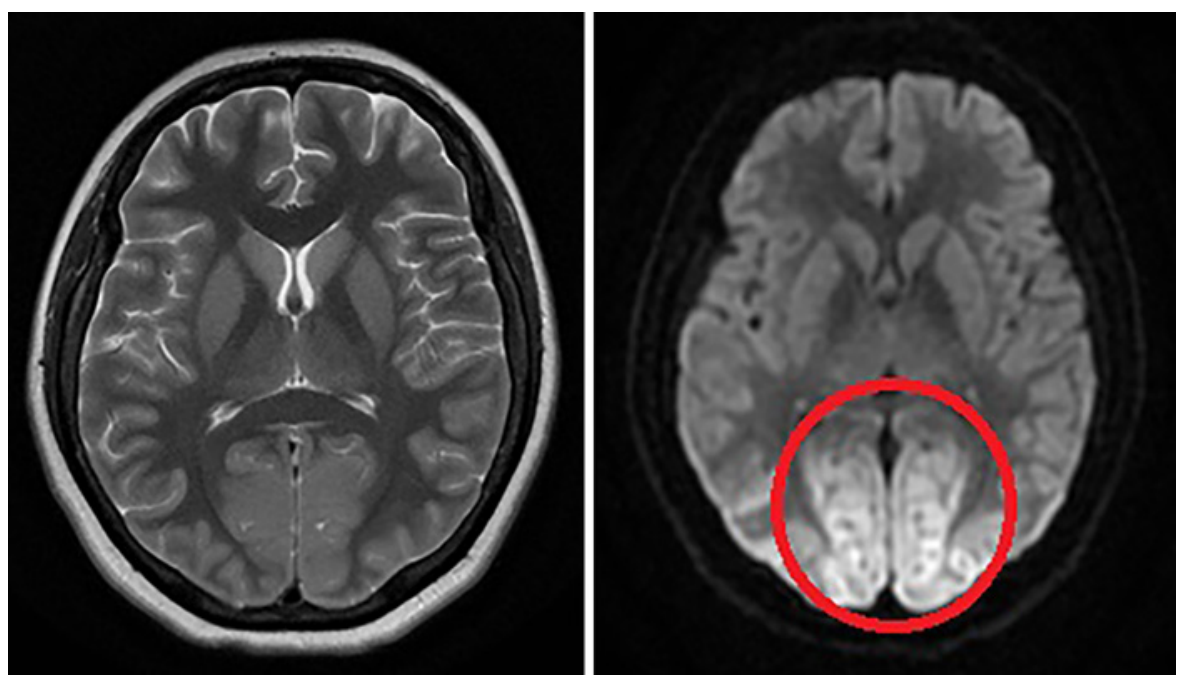

Fig. 3. Patient's MRI head scan 30 days after hospital admission (T2WI on the left and FLAIR on the right) with global brain atrophy and occipital lobe infarcts (circled). T2WI, T2-weighted image.
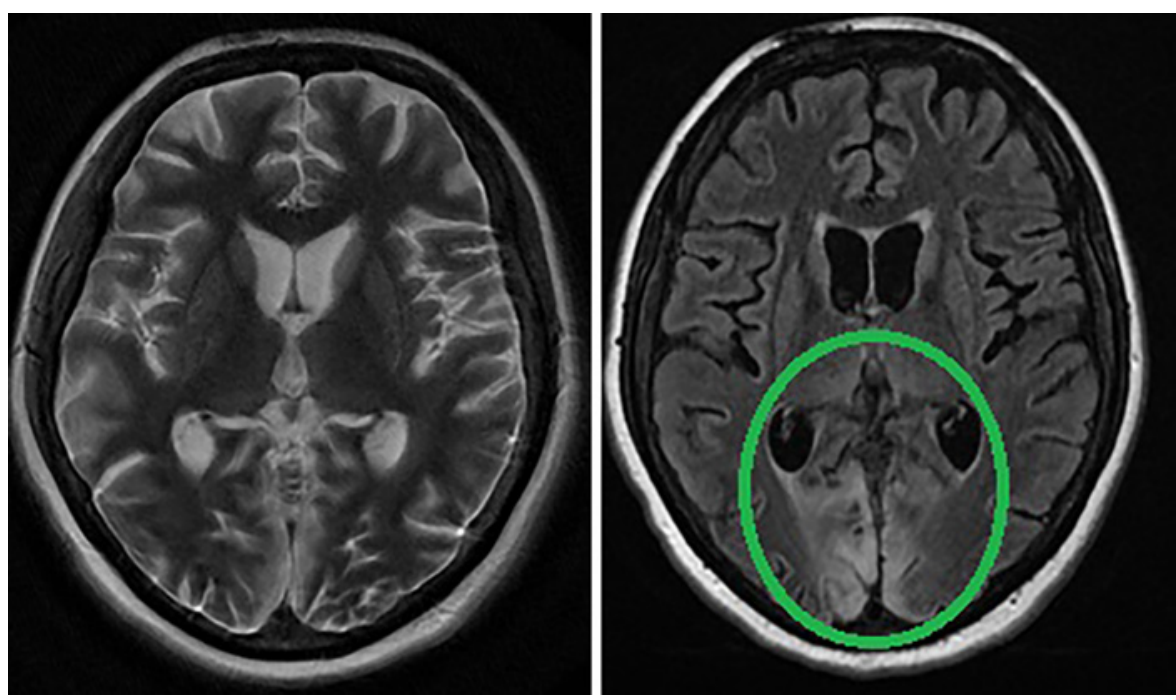

Treatment involves ventilation and oxygenation, while closely monitoring blood gases to prevent the damaging effects of prolonged hypoxia on the brain, blood pressure homeostasis that sometimes requires the use of vasopressors such as dopamine or norepinephrine to preserve brain perfusion $[8,9]$, close monitoring, and aggressive treatment of cardiac arrhythmias, ideally in an ICU setting. If intubation is required, the patient should be anaesthetised as sudden surge of catecholamines during the process of intubation can provoke ventricular arrhythmias [8]. Furthermore, one has to be cautious in administering large doses of catecholamines, such as adrenaline injections, during resuscitation as that can also provoke recurrent ventricular fibrillation [9].
Table 2. Differential diagnosis of bright (high signal in) basal ganglia on MRI head scans (DWI)

\author{
1. Carbon monoxide \\ 2. Methanol \\ 3. Cyanide \\ 4. Hyperammonemia (in liver disease) \\ 5. Hypoglycaemia \\ 6. Non-ketotic hyperglycaemia \\ 7. Osmotic myelinolysis \\ 8. Leigh's disease (mitochondrial problem) \\ 9. Wilson's disease (copper toxicity) \\ 10. Wernicke's encephalopathy (vitamin B1 deficiency)
}

DWI, diffusion-weighted image. 
Despite the presence of cerebral oedema after cardiorespiratory arrest following butane inhalation (indicating brain injury), prompt management of the hypoxia in an ICU and aggressive management of cardiac arrhythmias with anti-arrhythmic agents [9] can lead to a complete recovery with no sequelae $[9,10]$, but time is of the essence to obtain such an outcome. Any delay in such timely intervention may leave the patient with significantly impaired cognitive function as in our case or be left in a permanent vegetative state. A patient presenting to the A\&E with suspected butane toxicity should be admitted to the ICU even if no cardiac arrhythmias are evident initially on a standard 12-lead ECG for telemetry and close observation because they can later develop arrhythmias due to a catecholamine surge.

\section{Conclusion}

In summary, this case should warn us against being complacent when managing young people attending the A\&E with suspected solvent abuse even if they do not look seriously unwell at presentation.

\section{Statement of Ethics}

Ethical approval is not required for this case report as all data is anonymized and a formal written consent was obtained for publishing this case report. As the patient lacked the capacity to read or write, the written informed consent was obtained from the patient family for publishing the case report and any accompanying images.

\section{Conflict of Interest Statement}

The authors have no conflicts of interest to disclose.

\section{Funding Sources}

The authors did not receive any funding for this study.

\section{Author Contributions}

All the authors contributed equally to the article.

\section{Data Availability Statement}

All data generated or analysed during this study are included in this article. Further enquiries can be directed to the corresponding author.

\section{References}

1 Hegde AN, Mohan S, Lath N, Lim CC. Differential diagnosis for bilateral abnormalities of the basal ganglia and thalamus. Radiographics. 2011;31(1):5-30.

2 Ramsey J, Anderson HR, Bloor K, Flanagan RJ. An introduction to the practice, prevalence and chemical toxicology of volatile substance abuse. Hum Toxicol. 1989;8(4):261-9.

3 Oritani S, Zhu BL, Ishida K, Quan L, Taniguchi M, Fujita MQ, et al. Two autopsy cases involving asphyxia by butane inhalation. Forensic Toxicology. 2001;19:257-62.
4 Williams DR, Cole SJ. Ventricular fibrillation following butane gas inhalation. Resuscitation. 1998;37(1):43-5.

5 Bugra A, Das T. Postmortem diagnosis of myocardial infarction due to butane gas intoxication in a child: a case report. Am J Forensic Med Pathol. 2019;40(1):81-3.

6 Sato T, Nishioka H, Tsuboi K, Katagi M, Miki A, Saito T, et al. Detection of butane gas inhalation at 16days after hypoxic encephalopathy: a case report. Leg Med. 2017;29:34-7.
7 Anderson CE, Loomis GA. Recognition and prevention of inhalant abuse. Am Fam Physician. 2003;68(5):869-74.

8 Sen A, Erdivanli B. Cardiac arrest following butane inhalation. Anesth Essays Res. 2015; 9(2):273-5.

9 Edwards KE, Wenstone R. Successful resuscitation from recurrent ventricular fibrillation secondary to butane inhalation. Br J Anaesth. 2000;84(6):803-5.

10 Gunn J, Wilson J, Mackintosh AF. Butane sniffing causing ventricular fibrillation. Lancet. 1989;1(8638):617. 